\title{
A experiência da cidade de Pelotas no processo de preservação patrimonial
}

Liciane Machado Almeida* e Michele de Souza Bastos**

\section{Resumo}

Este artigo trata do relato da experiência de Pelotas na busca pela Preservação Patrimonial no município e demonstra que somente a persistência e a luta contínua foram capazes de garantir a permanência de exemplares arquitetônicos íntegros como verdadeiros testemunhos históricos da formação da cidade.

Durante muitos anos, defensores da preservação do patrimônio buscaram meios de resguardar a memória e a história da cidade. Muitos avanços e retrocessos ocorreram nesse longo período, que vai desde a instituição do II Plano Diretor do município, em 1980, até os dias atuais. Legislações específicas de preservação, aprovadas durante a década de 80 , foram tentativas que não se concretizaram, na prática, pela falta de consciência de grupos sócio-econômicos do município, envolvidos com a dinâmica de crescimento da cidade e, principalmente, pela descontinuidade de ações preservacionistas da administração pública, nesse período.

Porém, a partir do ano 2000, com a instituição de uma nova legislação mais integrada com a sociedade e com apoio político-administrativo efetivo, revigoram-se as forças e o processo de preservação patrimonial é, definitivamente, estabelecido na cidade. O reconhecimento de áreas urbanas como zonas de preservação e a proteção aos imóveis inventariados transformam gradativamente o modo de percepção do espaço urbano e o respeito ao preexistente passa a ser condicionante para novas inserções. $O$ incentivo à preservação do patrimônio estabelecido, através da isenção de IPTU, também é fator preponderante no resgate da cultura preservacionista, tanto pela recuperação do acervo histórico-cultural, como pela educação patrimonial promovida, através do contato direto com os detentores do patrimônio cultural da cidade.

Atualmente, Pelotas vivencia um momento positivo na área da preservação patrimonial, mas, é preciso manter a consciência de que esse é um processo 
permanente, em que a cada tempo são apresentados novos desafios que exigem novas conquistas.

Palavras-chave: Preservação patrimonial. Identidade cultural. Planejamento urbano.

\title{
The experience of Pelotas city in the process of cultural properties preservation
}

\begin{abstract}
This paper is about the experience of Pelotas City and its research for cultural properties preservation in the town. It shows that only hard work and persistence can guaranty the over lasting of real historic witnesses of the city formation.
\end{abstract}

In many years defenders of the cultural properties preservation have been trying to find means to protect the memory and the history of the city. Many advance and retrogress happened in this long period since the implementation of the II Master Plan, in the 1980's, until nowadays. Specific preservation laws, approved during 80th, were attempts that actually weren't realised either because of the nonpreservationist awareness of socio-economic groups in the city involved with the dynamic and the development of the town and specially because of the discontinuity of preservation actions of public administration in the mentioned period.

Although, in the 2000th, with the creation of a new legislation involved with the society and with effective politic-administrative support, the process of cultural properties preservation had definitely set up. The recognition of urban areas as preservation zones and the protection of inventoried properties, it had transformed gradually the perception of the urban place and the respect to the pre-existent environment, now considered for new interventions in the urban mean. The incentive for preservation of properties established through the exemption from building tax, is also a prominent factor in the rescue of the preservationist culture, such for recuperation of the historic-cultural properties, as for the patrimonial education promoted through the direct contact to the owners of the cultural properties. 
Nowadays Pelotas lives a good moment in the properties preservation area, but its important to maintain the conscience that this is a long and continuing process, where every time new challenges come up which always requires new victories.

Key words: Cultural properties preservation. Cultural Identity. Urban planning

A busca pela preservação é um processo de diferentes e difíceis estágios, que ultrapassam a aplicação de ações institucionais e de instrumentos legais preservacionistas. A realização dessa ação somente é possível quando o valor do "bem" a ser preservado é reconhecido pela comunidade a qual, identificando-se com o fim visado, interage no processo de valorização e torna real e efetiva a ação. Foi a partir desse entendimento que a luta pela preservação em Pelotas encontrou um caminho para a consolidação de seus objetivos e a realização de seus anseios preservacionistas.

\section{Contextualização histórico-cultural da cidade}

A formação urbana da cidade de Pelotas foi propiciada pelo desenvolvimento econômico gerado pela produção do charque, atividade que, até as primeiras décadas do século $X X$, passou a ser a principal fonte econômica de desenvolvimento da região. Localizada ao sul do Rio Grande do Sul (fig.01), Pelotas é hoje, apesar da estagnação econômica, considerada um atrativo pólo regional da metade sul do estado, principalmente na área educacional. Atualmente, com mais de 300.000 habitantes, convive com os problemas decorrentes de uma cidade de porte médio. O crescimento desordenado, sem desenvolvimento econômico compatível, provocou a desqualificação do espaço urbano, descaracterizando o acervo arquitetônico patrimonial e relegando a história da cidade ao esquecimento durante um longo período.

Estudos sobre a história de Pelotas, realizados por pesquisadores como Mário Osório e Ester Gutierrez (1), confirmam os dados de que foi a partir do acúmulo de riquezas gerado pela produção do charque (2) que o núcleo urbano se desenvolveu. Como essa atividade provocava odores desagradáveis no entorno das fazendas, os 
senhores proprietários das charqueadas buscaram um local afastado para suas moradias e, a partir do forte contato que tinham com a Europa, principalmente Paris, transformaram o pequeno núcleo colonial que ali existia em um próspero povoado, segundo os moldes do ecletismo europeu daquela época.

A arquitetura residencial urbana de Pelotas, que foi em grande parte produzida por mão-de-obra escrava, assim como ocorreu na maioria das cidades brasileiras, teve como base o parcelamento do solo de origem portuguesa do tipo reticulado com arruamento bastante regular, que resultou em lotes de pouca testada e muita profundidade. A uniformidade dos lotes condicionou a uniformidade das construções que eram erguidas sobre os limites laterais do terreno e sobre o alinhamento predial, constituindo, assim, elementos definidores das vias públicas (LEMOS, 1989, p.22).

A cidade constitui-se, então, como espaço de moradia e representação para os ricos charqueadores. O processo de produção do charque, que era realizado nas charqueadas de novembro a abril, liberava por largo espaço de tempo tanto os senhores quanto os escravos, tendo sido estes utilizados na construção da cidade (MOURA, 1998, p.30).

Porém, foram as influências locais, somadas às características tradicionais ecléticas da Europa, que tornaram Pelotas uma cidade valorizada culturalmente, com identidade própria.

Atualmente podemos com facilidade identificar, na arquitetura, as duas fortes correntes histórico-culturais de formação da cidade de Pelotas: uma às margens do Arroio Pelotas (3), que representa o período colonial, onde se encontram localizadas as charqueadas (fig.02 e 03), e outra localizada no centro histórico da cidade, correspondente aos primeiros loteamentos urbanos, representante do período eclético (fig.04 e 05). São os exemplares remanescentes desses dois períodos que se busca, através da preservação, resguardar e transformar em agentes ativos deste novo tempo, capazes não apenas de guardar o passado, mas de também participar do presente, construindo o futuro.

Considerando o grande acervo histórico, representativo desses períodos de formação da cidade, que já foi gradativamente destruído, talvez possamos compreender a luta pela permanência do que ainda está inserido em nosso meio, 
que ainda fala de um passado que remete à história de construção da cidade e que, principalmente, produz, constrói a necessária identidade cultural.

\section{A trajetória da preservação em Pelotas}

Fazendo um paralelo com a história da preservação em nível nacional, podemos dizer que Pelotas construiu sua memória preservacionista seguindo as mesmas premissas e os mesmos conceitos adotados no país. As primeiras ações efetivamente instituídas reportam-se ao tombamento de bens imóveis e, assim como ocorreu em todo território nacional, o reconhecimento desses bens como patrimônio cultural deu-se pelo seu caráter de monumento arquitetônico. Somente com a ampliação do conceito de patrimônio, favorecido pelo processo de democratização e inclusão da sociedade nas práticas de políticas públicas, é que o caráter urbano e o valor de conjunto são inseridos neste contexto.

O distanciamento temporal que ocorreu entre as práticas em nível nacional e local se justifica, de certa maneira, naquele momento, pela ausência de autonomia administrativa municipal para gerenciar essas ações, o que foi superado com a promulgação da constituição de 1988, que atribuiu aos municípios competência para legislar sobre assuntos de interesse local, possibilitando, assim, a elaboração de leis específicas de proteção ao patrimônio.

Em Pelotas, já no inicio dos anos 80, com a aprovação do II Plano Diretor da cidade, são introduzidos os primeiros conceitos de preservação em nível municipal. O novo instrumento de planejamento urbano, apesar de apresentar uma base teórica com objetivos preservacionistas, confronta-se com essa premissa de conservação do patrimônio ao implantar um regime urbanístico incentivador da ocupação e renovação do uso do solo para a área central, região de maior concentração de bens com valor histórico-cultural. O índice de aproveitamento mais elevado e altura livre estabelecidos para essa área, definida como ZCC - zona de comércio central -, na verdade geram um acelerado processo de destruição do acervo histórico-cultural registrado através da arquitetura, provocando a substituição de construções residenciais de um ou dois pavimentos por edifícios em altura. As constantes demolições sem autorização e sem controle efetivo do poder público, juntamente com alterações no parcelamento do solo através de unificações de lotes, provocam 
uma grande descaracterização e desqualificação do espaço urbano, que passa de uma paisagem homogênea, com uma linguagem arquitetônica padrão, ao predomínio de uma paisagem heterogênea, com construções que não mais se integram, pois as novas inserções não consideram 0 preexistente como condicionante para sua implantação. Considerando a época de elaboração do II Plano Diretor, reconhecemos como precursoras as inovações teóricas conceituais preservacionistas adotadas. A declaração da necessidade de: criação das zonas de preservação, tombamento de alguns exemplares, elaboração do cadastro de prédios de interesse patrimonial e a preocupação com o entorno dos prédios históricos são alguns dos principais aspectos contidos no novo plano. Cabe destacar que somente 20 anos mais tarde, como depois veremos, é que efetivamente estas ações são postas em prática.

Em 1982, com base no decreto federal 25/37, é instituído o tombamento em nível municipal através da aprovação da lei no 2708/82, que também cria o Conselho Municipal do Patrimônio Histórico e Cultural (COMPHIC), prevê a isenção de IPTU aos prédios tombados e a possibilidade de transferência do direito de construir equivalente ao potencial construtivo da zona. "Pelotas estava na vanguarda dos acontecimentos culturais quando contava com este instrumento legal para proteger seu patrimônio de qualidade e de quantidade tão expressiva" (ROIG, 1997). Porém, forças político-econômicas locais produtoras do espaço urbano e contrárias à preservação promoveram, em 1988, a aprovação de uma nova lei 3128/88, que, alterando a anterior, provocou um retrocesso no processo que estava sendo implantado. Cabe destacar que, durante o período de atuação do Conselho Municipal, foram analisados 10.000 prédios, dos quais 1189 foram cadastrados no inventário e 236 tombados provisoriamente em 1987.

A principal alteração introduzida pela Lei $3128 / 88$ diz respeito ao condicionamento do tombamento definitivo à apreciação da Câmara Municipal, o que transformou um ato tipicamente administrativo, da competência do poder executivo, como determina o decreto 25/37, em conduta dependente do Poder Legislativo. Com isso, dos 236 prédios com tombamento provisório, decretado em 1987, somente 16 foram definitivamente protegidos, sendo que, destes, quatro são tombados em nível federal (Casarões no 02, 06, 08 e o Teatro Sete de Abril) e um em nível estadual (Casa da 
Banha). A mesma lei ainda estabelece a criação de um Conselho Revisor, ao qual foi atribuída a competência de avaliar as decisões originárias do COMPHIC. Constituído, em sua maioria, por representantes do mercado imobiliário, o Conselho Revisor desarticulou o grupo de preservação e impediu que se avançasse à luta pela preservação patrimonial.

Quase uma década depois, há uma tentativa de retomar o esforço no sentido de preservação do patrimônio, com a aprovação de uma nova lei municipal 4096/96 que, apesar de ter um cunho mais democrático e demonstrar claramente a intenção de preservar, não consegue efetivamente atingir os objetivos propostos. A extinção de alguns artigos das antigas legislações e a criação de um novo Conselho Municipal de Cultura, o CONCULT, substituindo o COMPHIC, provoca algumas dificuldades nas interpretações das legislações, favorecendo os grupos contrários à preservação.

Porém os preservacionistas, representados por técnicos do Poder Público Municipal e da Universidade Federal de Pelotas, voltam a mobilizar-se e, com o início de um novo tempo, em que a comunidade começa a sentir-se parceira dessa luta, elaboram um Sistema Municipal de Preservação Cultural - SIMPAC, que aborda as mais variadas questões referentes à defesa do patrimônio cultural de Pelotas, como formas de preservação, cadastro e classificação dos bens imóveis de interesse cultural, incentivos, restrições, avaliação do entorno para novas inserções, etc. Depois de muita discussão envolvendo vários setores da sociedade, esse sistema bastante amplo foi aprovado, com restrições significativas comparando à integridade do projeto original, resultando na Lei 4568/2000, que é o atual instrumento legal utilizado pelo Poder Público.

Como já se fez referência, foram necessários 20 anos para que as premissas de preservação abordadas no Plano Diretor de 1980 fossem efetivamente regulamentadas e praticadas. A partir da lei 4568/00, ficam instituídas as Zonas de Preservação do Patrimônio Cultural - ZPPCs (fig.06), são listados os bens integrantes do inventário e torna-se possível o controle das descaracterizações promovidas nos bens patrimoniais, assim como a possibilidade de regramento das futuras intervenções nos prédios inventariados e nos seus confrontantes laterais. As 
ZPPCs foram delimitadas seguindo o processo de formação e desenvolvimento urbano de Pelotas e representam os primeiros loteamentos executados na cidade. Os imóveis cadastrados no inventário do patrimônio cultural (fig.07) atualmente somam mais de 1700 prédios, que estão, na sua maioria, localizados nas zonas de preservação.

Somado a este instrumento legal, o município, neste período, passou por uma transformação político-administrativa que possibilitou o avanço nos debates e viabilizou a prática de ações em defesa efetiva do patrimônio local. A criação da Secretaria Municipal de Cultura, atual órgão responsável pelas políticas de preservação no município, e a ampliação do quadro técnico profissional do departamento de preservação através de contratações via concurso público, foram ações fundamentais para acelerar o processo de resgate do patrimônio histórico da cidade.

Atualmente todas as ações de preservação estão enfocadas em dois objetivos específicos: o primeiro visa garantir a permanência dos exemplares remanescentes, tombados e inventariados, como testemunhas de um período, guardiões da memória e da história da cidade, e o segundo pretende qualificar o entorno dos bens de referência histórico-cultural através de mecanismos de reconhecimento e valorização desse acervo. Para isso, a Secretaria Municipal de Cultura de Pelotas, através da Diretoria Memória e Patrimônio, vem desenvolvendo seu trabalho, ampliando suas ações e concretizando a preservação na cidade, com a participação de outras secretarias, principalmente de planejamento urbano, e universidades locais.

\section{Ações atuais de Preservação}

\subsection{A busca pela superação das dificuldades ainda existentes}

Dando continuidade às ações até então instituídas, em 2002, a revisão no Código Tributário do município prevê a possibilidade de isenção de IPTU aos imóveis integrantes do inventário, através da lei 4878/2002, atual 5146/2005. Apesar de este ser um instrumento fiscal usualmente utilizado como incentivo à preservação, sabemos que, na maioria dos casos, não se atingem os objetivos propostos e, 
quando isso ocorre, demanda muito tempo para se perceberem as alterações no contexto urbano.

Porém, no caso específico de Pelotas, em apenas quatro anos de vigência da lei já existe um número expressivo de imóveis inseridos no processo de recuperação e conservação, via isenção de IPTU. Gradativamente, as melhorias estão sendo percebidas pela comunidade, estão contagiando outros proprietários (fig.08) e qualificando a paisagem urbana. Os procedimentos administrativos para a solicitação de isenção de IPTU envolvem duas secretarias, Finanças e Cultura, sendo de responsabilidade da última a avaliação e o parecer final. Para a concessão do benefício, os proprietários de imóveis patrimoniais devem fazer a solicitação anualmente. A partir das solicitações, os técnicos da Secretaria de Cultura realizam vistoria externa nos imóveis e avaliam seu estado de conservação e manutenção das características arquitetônicas, elaboram um relatório com considerações e recomendações de adequações e conservação, que é enviado aos proprietários; os mesmos devem, até a próxima vistoria, executar pelo menos parte das solicitações para manter o benefício. A intenção é simples e tem funcionado: o recurso do imposto deve ser revertido em melhorias no imóvel e como incentivo à recuperação do prédio, todas as solicitações encaminhadas pela primeira vez têm o benefício concedido. Nos casos em que as recomendações não são cumpridas, a equipe técnica faz contato direto com o responsável pelo imóvel e, quando há interesse de recuperação do imóvel, concede novamente o benefício, que fica condicionado ao cumprimento das recomendações expressas em um termo de compromisso assinado pelo proprietário; caso contrário, a isenção não é concedida para aquele exercício, podendo, no ano seguinte, novamente ser solicitada; devendo, então, passar pelo mesmo processo de avaliação.

A isenção de IPTU, da forma como está sendo aplicada em Pelotas, é hoje um instrumento que está atingindo mais objetivos do que os previamente estabelecidos. Além da recuperação de muitos imóveis é a partir do contato com o proprietário, possibilitado por este instrumento, que se tem conquistado a inclusão da sociedade no processo de preservação, através da educação patrimonial. 
Apesar do eficaz e cuidadoso processo de preservação patrimonial desenvolvido, ainda ocorrem situações de descontentamento e até mesmo de revolta por parte de alguns proprietários, mas de modo geral há uma compreensão e uma aceitação dos procedimentos adotados. Até mesmo os representantes da construção civil já adquiriram uma percepção positiva com referência à preservação, entendendo-a como mecanismo de desenvolvimento e não apenas de congelamento da economia e atraso do progresso, como ocorria anteriormente.

Outro instrumento a ser regulamentado pela Prefeitura de Pelotas, para a proteção e guarda dos bens imóveis constantes no Inventário do Patrimônio Histórico e Cultural da cidade, é a classificação destes em diferentes níveis de preservação, visando suprir uma demanda de diferenciação entre os prédios inventariados de acordo com suas características arquitetônicas e espaciais, haja vista que as zonas de preservação são regiões bastante amplas, que possuem características urbanas diferenciadas. Essa classificação vem nortear as intervenções, os incentivos e regimes urbanísticos em áreas de preservação e de interesse cultural no município.

Em síntese, os níveis de preservação objetivam estabelecer diferentes instâncias de proteção, orientando os graus de intervenções possíveis nos prédios inventariados, e, conseqüentemente, em seu entorno, sem que venham a descaracterizá-los irreversivelmente ou de modo que se perca a leitura de seu contexto na paisagem urbana.

A necessidade de sistematização dessa classificação fez com que fosse desenvolvido um método de análise e avaliação objetivo e criterioso. A elaboração desse método partiu da definição de três categorias de análise, em que se avalia sua relação intralote, a leitura da paisagem onde o bem está inserido e o grau de descaracterização que apresenta, considerando, para cada uma, a seguinte definição:

Relação intralote: analisa as características arquitetônicas e tipológicas do bem, avaliando seus elementos compositivos e sua identificação com alguma tipologia arquitetônica representativa; 
Leitura da paisagem: analisa o contexto urbano de localização do bem, avaliando questões como continuidade dos elementos horizontais, ritmo dos elementos verticais, equilíbrio, hierarquia e homogeneidade da paisagem;

Descaracterizações: analisa as intervenções ocorridas no bem, avaliando seu impacto e a possibilidade ou não de reversibilidade das mesmas.

Esse instrumento encontra-se em processo de elaboração e prevê a instituição de quatro níveis de preservação, sendo classificados em:

Nível 1 de preservação: os imóveis componentes do Patrimônio Cultural que ensejam a preservação de suas características arquitetônicas, artísticas e decorativas internas e externas. Os bens enquadrados neste nível não poderão, em hipótese alguma, ser destruídos, descaracterizados ou inutilizados, podendo vir a ser tombado. São muitas vezes relevantes por sua conotação histórica;

Nível 2 de preservação: os imóveis componentes do Patrimônio Cultural que ensejam a preservação de suas características arquitetônicas, artísticas e decorativas externas, ou seja, a preservação integral de sua(s) fachada(s) pública(s) e volumetria, excetuando-se alguns casos em que, em decorrência de sua ambiência urbana, com predomínio de atividades comerciais, será permitido algum tipo de intervenção na fachada, desde que orientada e de acordo com critérios do departamento de preservação. Esses imóveis poderão sofrer intervenções internas, desde que mantidas e respeitadas suas características externas;

Nível 3 de preservação: os imóveis componentes do Patrimônio Cultural que ensejam sua preservação devido a características de acompanhamento e complementaridade de imóveis classificados como de nível 1 ou 2 e/ou de complementaridade de determinado contexto urbano, podendo vir a sofrer intervenções internas e externas, acrescentando ou não novos elementos, desde que não sejam descaracterizadas sua volumetria e ambiência já configurada com os imóveis de nível 1 e 2;

Nível 4 de preservação: os imóveis componentes do Patrimônio Cultural cujas características arquitetônicas, artísticas e decorativas não apresentam caráter de excepcionalidade, acompanhamento e complementaridade arquitetônica ou, tendo esse caráter, encontram-se em tal grau de descaracterização que podem vir a ser substituídos sem acarretar maiores perdas ao patrimônio histórico e cultural da cidade. Sua preservação ocorre por registro no Inventário do Patrimônio Cultural, e a 
substituição por outra edificação será regulamentada pelos instrumentos urbanísticos da área, considerando o contexto urbano onde estão inseridos, sem descaracterizar a volumetria e ambiência já configuradas. Assim, os bens enquadrados neste nível poderão sofrer alterações internas e externas, assim como demolições parciais ou totais do imóvel.

Considerando que todas as análises e aprovações de projeto atualmente solicitadas e localizadas nas zonas de preservação são avaliadas pelo departamento de preservação, a conclusão desse trabalho de classificação em níveis de preservação será fundamental para agilizar, padronizar e sistematizar a demanda existente.

Assim como na avaliação do processo de isenção de IPTU, os procedimentos de análise de projeto têm possibilitado o contato direto com responsáveis técnicos e proprietários. Dessa forma, cria-se uma política de orientação e convencimento dos detentores desse patrimônio e constrói-se mais um mecanismo de resgate e revitalização do bem cultural para a qualificação da ambiência urbana.

A realização das análises e aprovações de projetos tem se desenvolvido em parceria com a Secretaria de Urbanismo, através do Escritório Técnico do Plano Diretor (ETPD), o qual foi reestruturado recentemente com o objetivo de integrar os diversos setores administrativos do poder público, padronizando os critérios e a forma de percepção do espaço urbano e transformando planejamento e preservação em correntes que atuam na mesma direção, que buscam o mesmo objetivo: "qualificação urbana".

Com essa compreensão é que o município está em pleno desenvolvimento do III Plano Diretor de Pelotas, que priorizará a preservação não apenas conceitualmente, como no Plano Diretor de 1980, mas também através da definição de instrumentos urbanísticos concretos, que assegurem a permanência do acervo remanescente. Para isso estão sendo identificadas e mapeadas áreas de especial interesse cultural no contexto urbano e rural como representantes de espaços com significação relevante, a partir de suas características morfológicas, funcionais, culturais e paisagísticas. A determinação de diretrizes urbanísticas para essas áreas, considerando as particularidades de cada região, visa promover a requalificação da 
paisagem urbana e a identificação de potencialidades e prioridades que vão auxiliar a tomada de decisões político-administrativas do município.

Dentre as muitas ações em desenvolvimento, a inclusão de Pelotas no Programa Monumenta, do governo federal, foi e está sendo fundamental na concretização dos anseios preservacionistas da cidade, atraindo o olhar da comunidade e despertando a curiosidade sobre a história de Pelotas. Está prevista a recuperação e requalificação da Praça Coronel Pedro Osório e dos principais prédios localizados no seu entorno (fig.09), incluindo também o Largo do Mercado Público. Algumas dessas obras já foram concluídas - Fonte das Nereidas (Chafariz localizado no centro da Praça Coronel Pedro Osório), Grande Hotel e Casarão no 2 -, e outras estão em fase de execução ou licitação - Teatro Sete de Abril, Prefeitura Municipal, Praça Coronel Pedro Osório e Largo do Mercado. Como a intenção do programa vai além da recuperação física de prédios e monumentos históricos, outras ações culturais, já aprovadas, estão por serem postas em prática ainda durante o ano de 2006, via recursos do Programa Monumenta. Os cinco projetos aprovados, em 2005, atingem as áreas de música, dança, teatro, artes plásticas, qualificação profissional, reconhecimento da cultura local e educação patrimonial, envolvendo diversos segmentos da sociedade para sua execução através de parcerias. Dentre estes, destacamos o projeto "Inventário de Referência Cultural - Produção de Doces Tradicionais Pelotenses", o qual visa, através de uma pesquisa científica, com metodologia fornecida pelo IPHAN, identificar e registrar o modo tradicional do "saber" e "fazer" doces típicos pelotenses (fig.10). A inclusão de um trabalho que versa sobre o patrimônio imaterial da cidade demonstra o quanto Pelotas está atenta às questões conceituais de Patrimônio e disposta a participar de todos os avanços nesse sentido.

Pelo exposto, é possível perceber que, durante muitos anos, ações isoladas buscaram promover a preservação na cidade, sem obterem resultados significativos; instrumentos urbanísticos e legislações específicas de preservação foram exaustivamente elaborados, mas sem uma compreensão de seus objetivos não puderam ser efetivamente aplicados. A conquista da preservação em Pelotas somente começou a frutificar quando as ações passaram a envolver diversos segmentos da sociedade, somando esforços do poder público, iniciativa privada e 
população em geral, e quando, além da recuperação física do acervo histórico, se priorizou o reconhecimento deste enquanto patrimônio, promovendo o resgate da identidade cultural através do conhecimento.

Apesar do momento promissor, há muito a ser feito e, se realmente quisermos que a preservação se torne uma prática permanente, ainda precisamos transformá-la em sinônimo de desenvolvimento econômico do município, associando ainda mais ao planejamento urbano e à preservação patrimonial.

"Só se preserva o que se ama, só se ama o que se conhece..." (Carta de Pelotas)

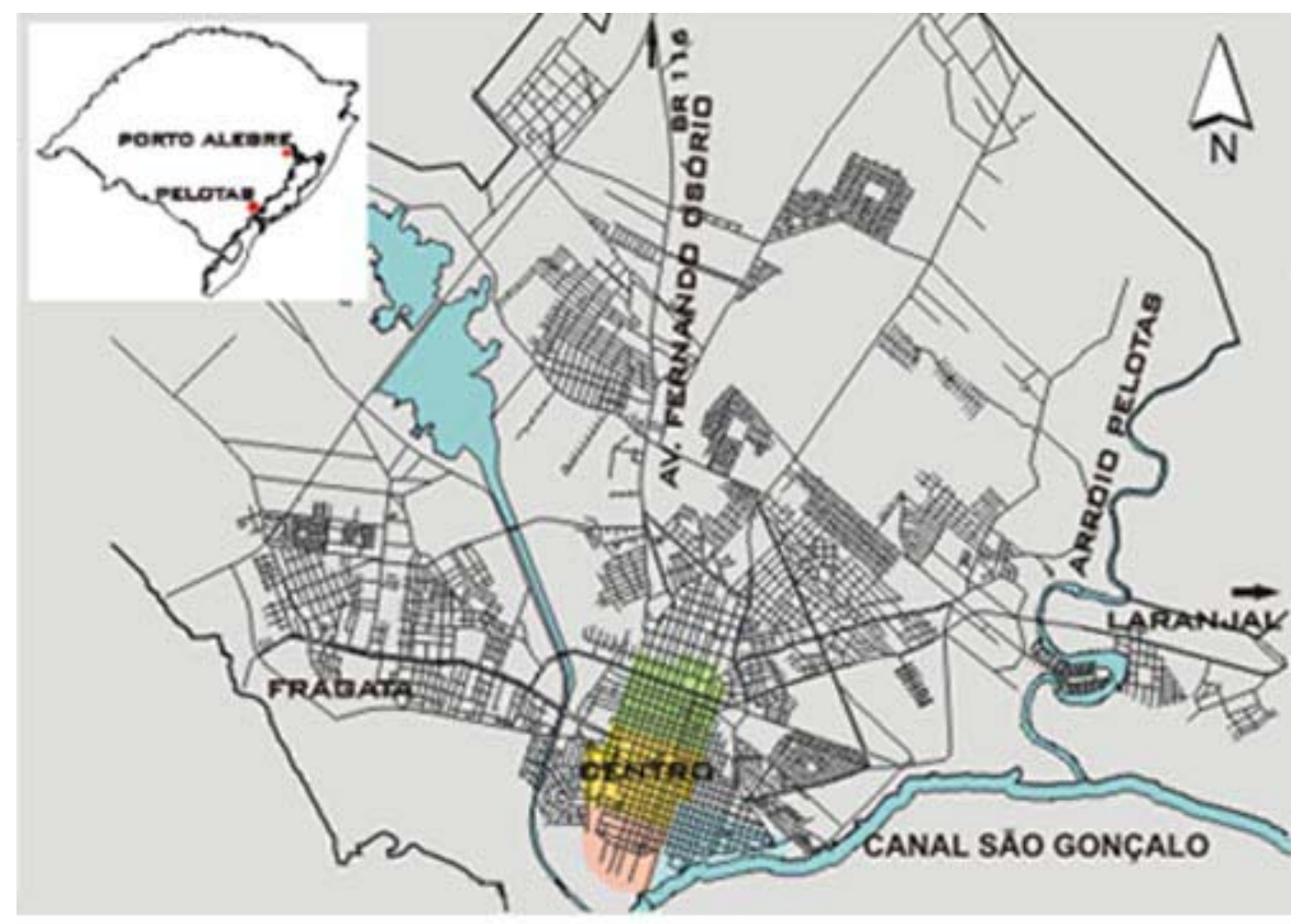

FIGURA 1 - Mapa da área urbana do município, com a localização dos quatro primeiros loteamentos da cidade, correspondentes as quatro Zonas de Preservação de Pelotas. Fonte: Acervo SECULT. 


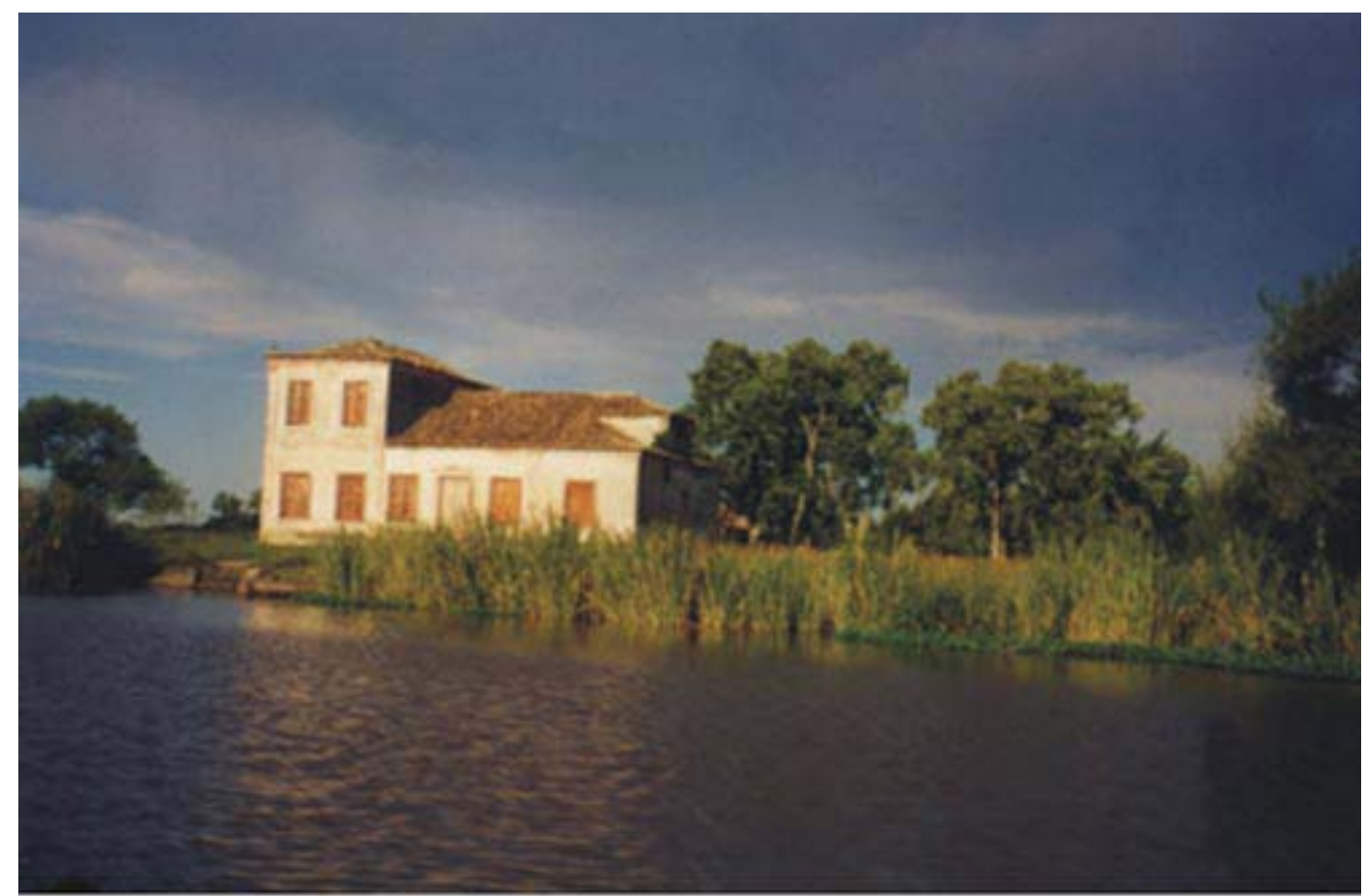

FIGURA 2 - Arroio Pelotas, área reconhecida como Patrimônio Cultural do Estado do Rio Grande do Sul através da Lei 11895/2003, com vista para a Charqueada do Barão de Butuí. Fonte: Acervo FAURB. 


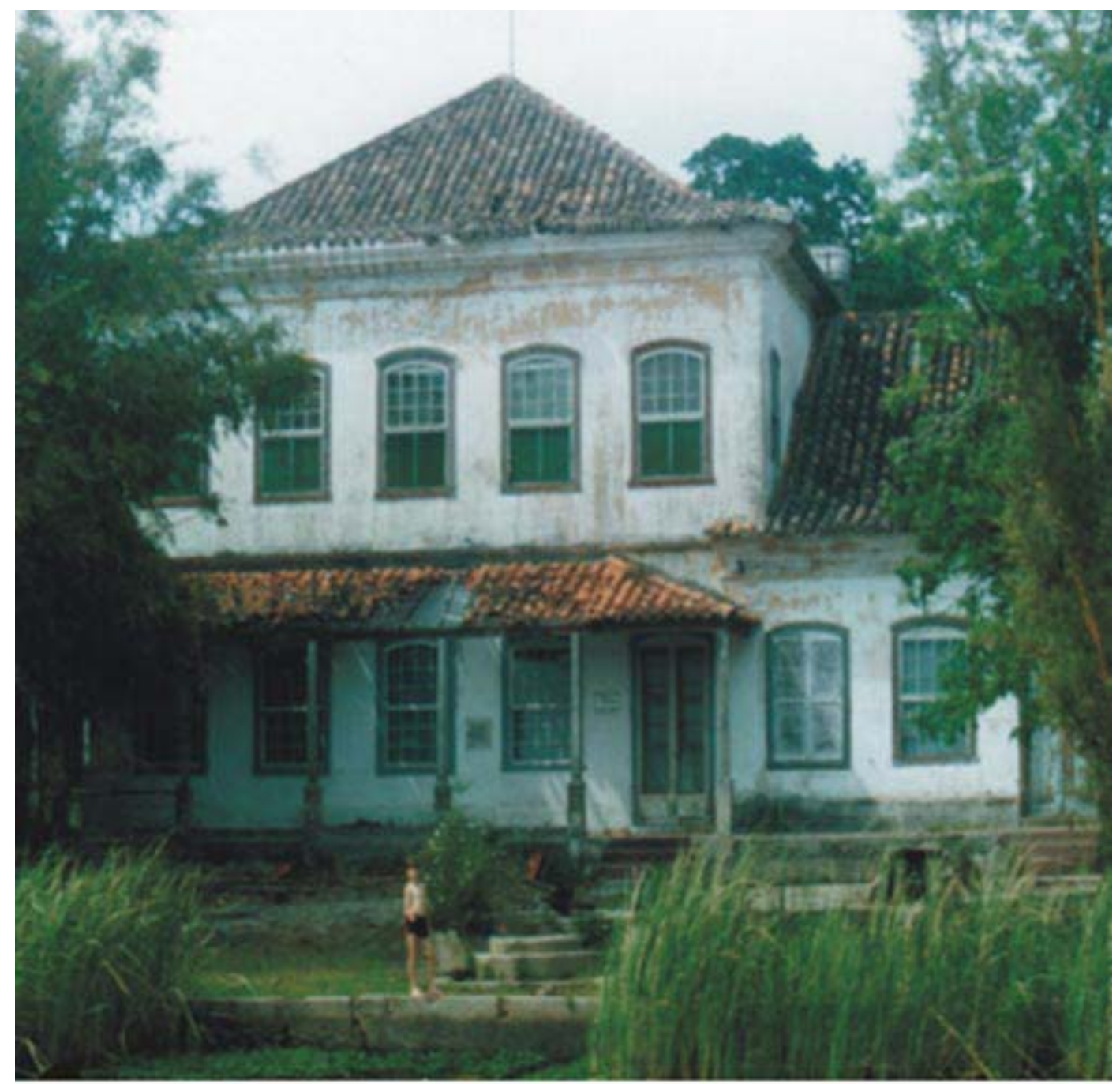

FIGURA 3 - Imagem da Charqueada do Barão de Jarau a partir das margens do Arroio Pelotas. Fonte: Acervo FAURB. 


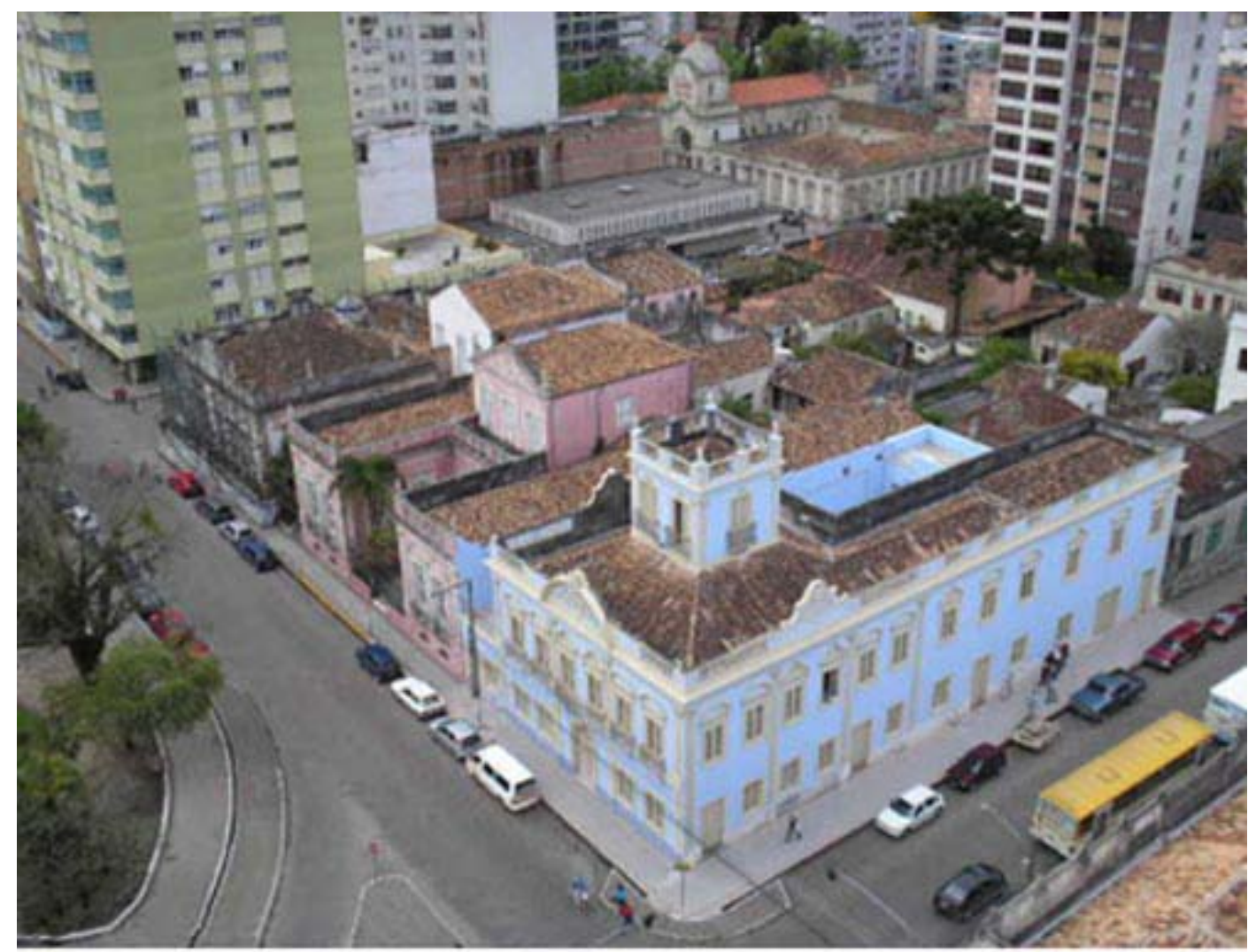

FIGURA 4 - Casarőes n 02, 06 e 08 situados à Praça Coronel Pedro Osório, conjunto eclético tombado pelo IPHAN com registro no livro das Belas Artes insc. $n^{\circ}$ 526 de 15/12/1977 e no livro Arqueológico Etnográfico e Paisagístico insc. $n^{\circ} 070$ de 15/12/1977. Fonte: Acervo SECULT.

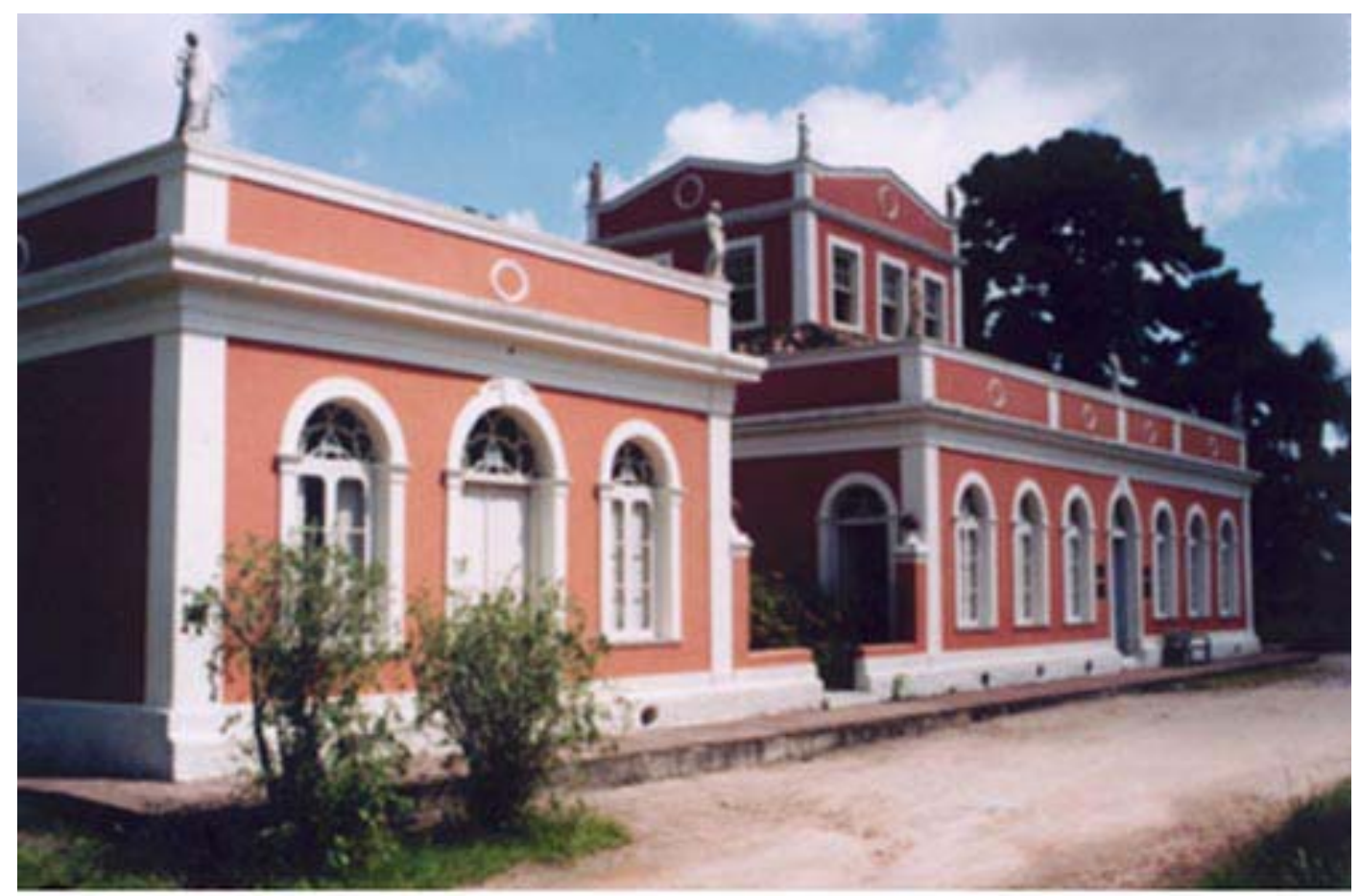

FIGURA 5 - Solar da Baronesa, bem tombado em nível municipal, implantado em extensa área verde, atualmente parque e museu municipal. Fonte: Acervo SECULT. 


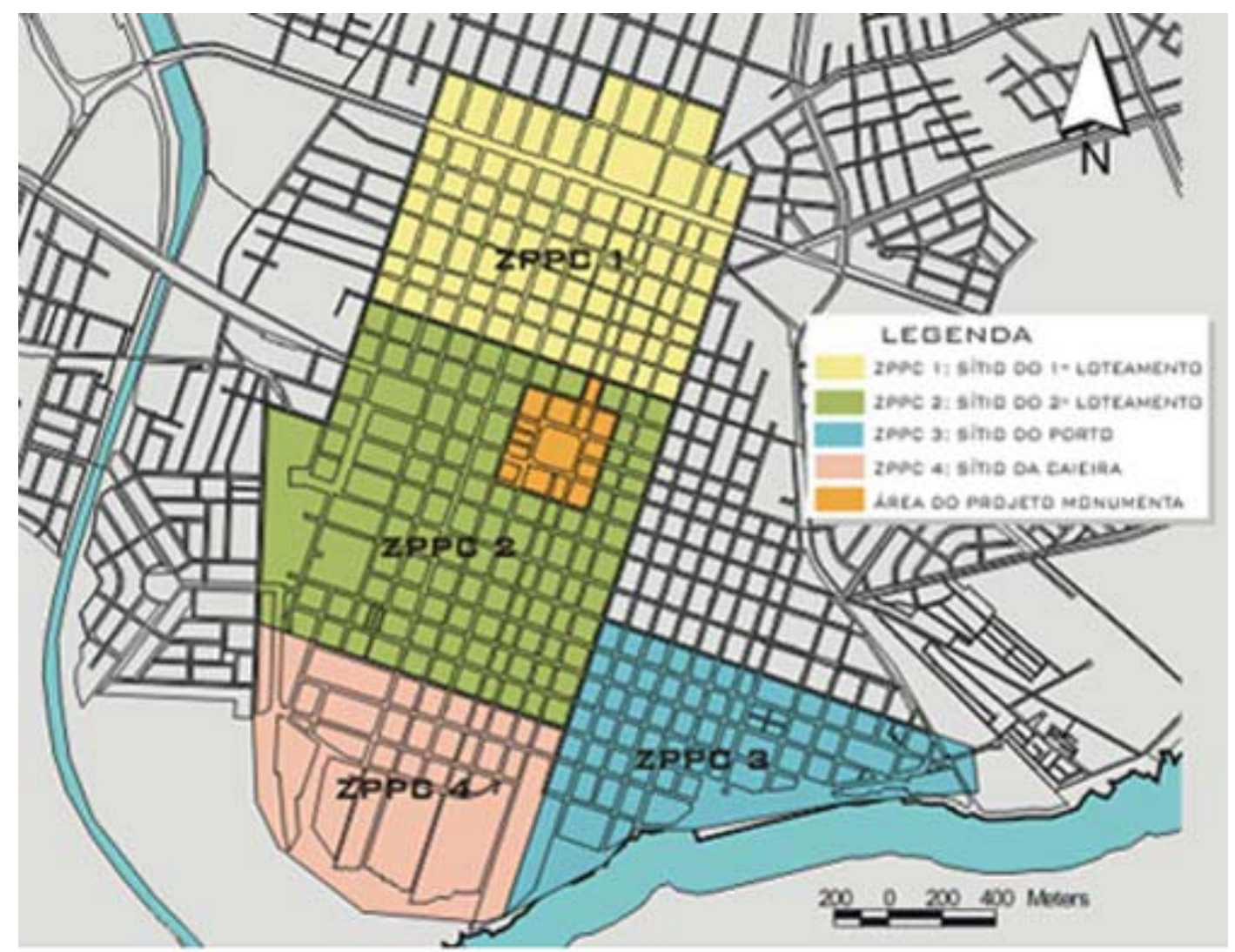

FIGURA 6 - Mapa com a delimitaçăo das Zonas de Preservação - ZPPCs, área de maior concentração dos prédios históricos de Pelotas. Fonte: Acervo SECULT.

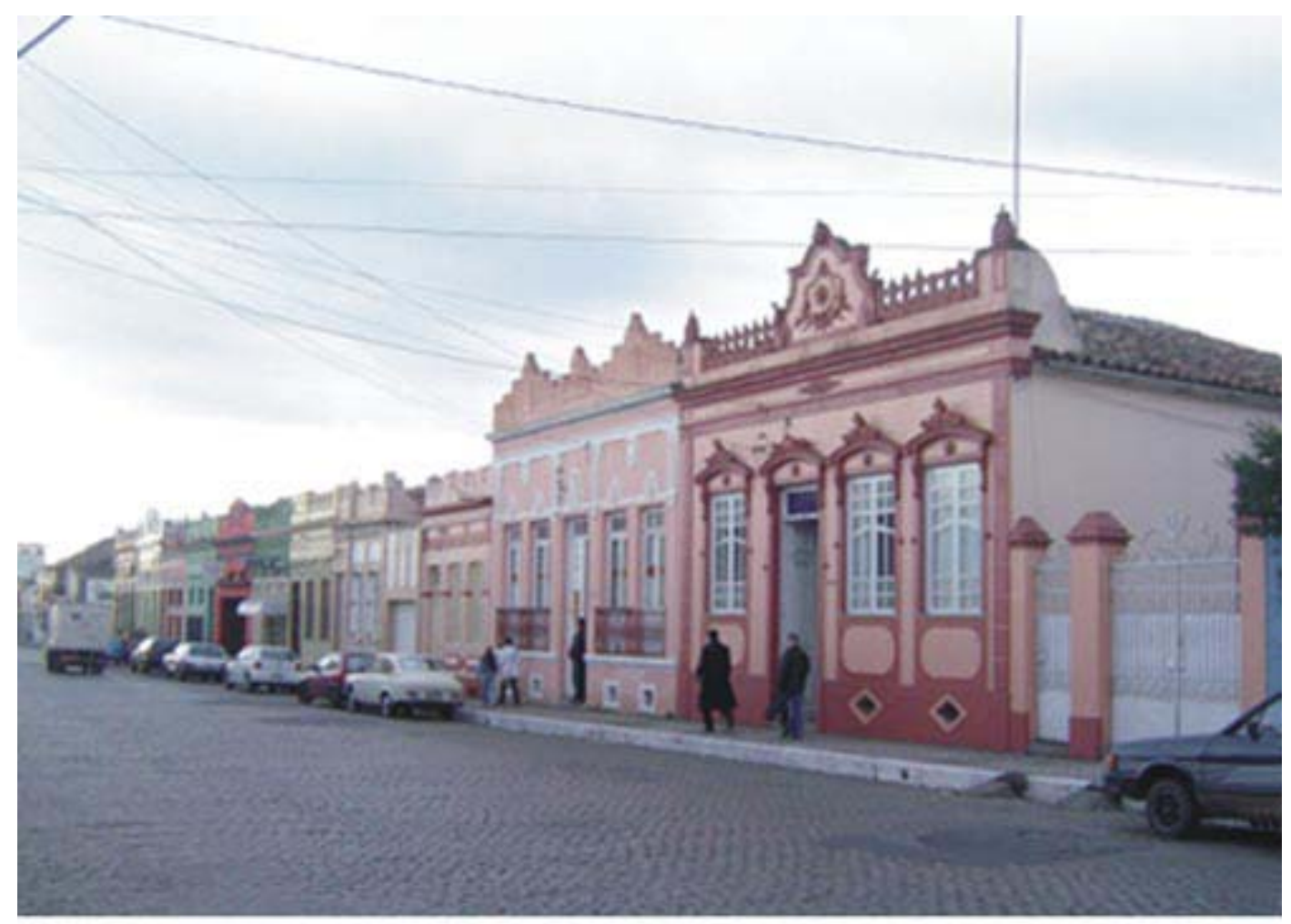

FIGURA 7 - Conjunto arquitetônico remanescente em estilo eclético situado à rua D. Pedro II, um dos quarteiröes íntegros na cidade, com poucas descaracterizações em suas edificaçőes. Fonte: Acervo SECULT. 

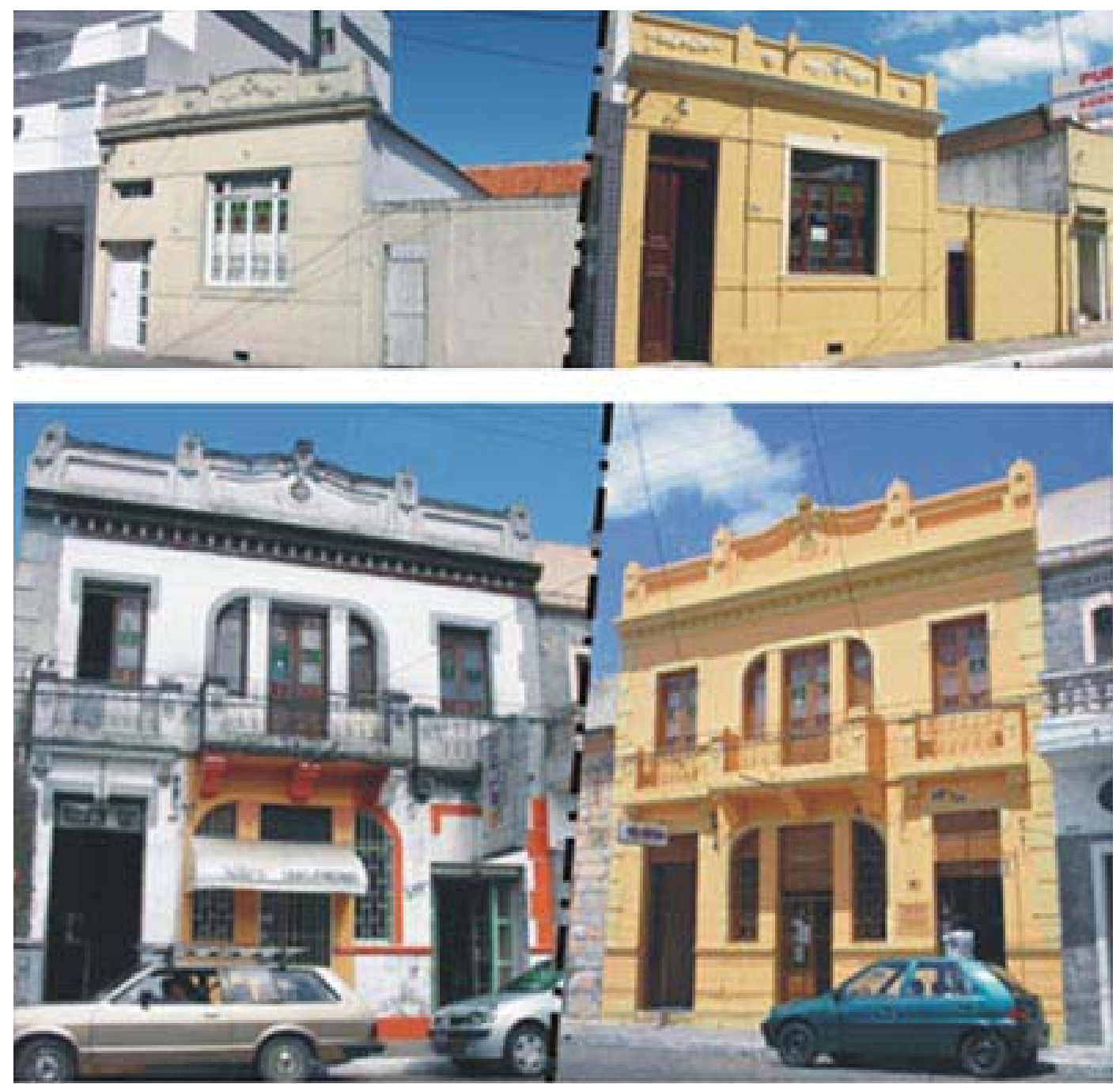

FIGURA 8 - Imóveis inventariados que aderiram ao processo de recuperação do prédio a partir da isenção de IPTU, verifica-se a adequação de pintura e aparato publicitário. Acima, na rua Félix da Cunha, 955, o edificio em 2002 (esquerda) e em 2004 (direita). Abaixo, a transformação do imóvel 514 da rua Quinze de Novembro, numa foto de 2004 (esquerda) e outra de 2005 (direita). Fonte: Acervo SECULT. 


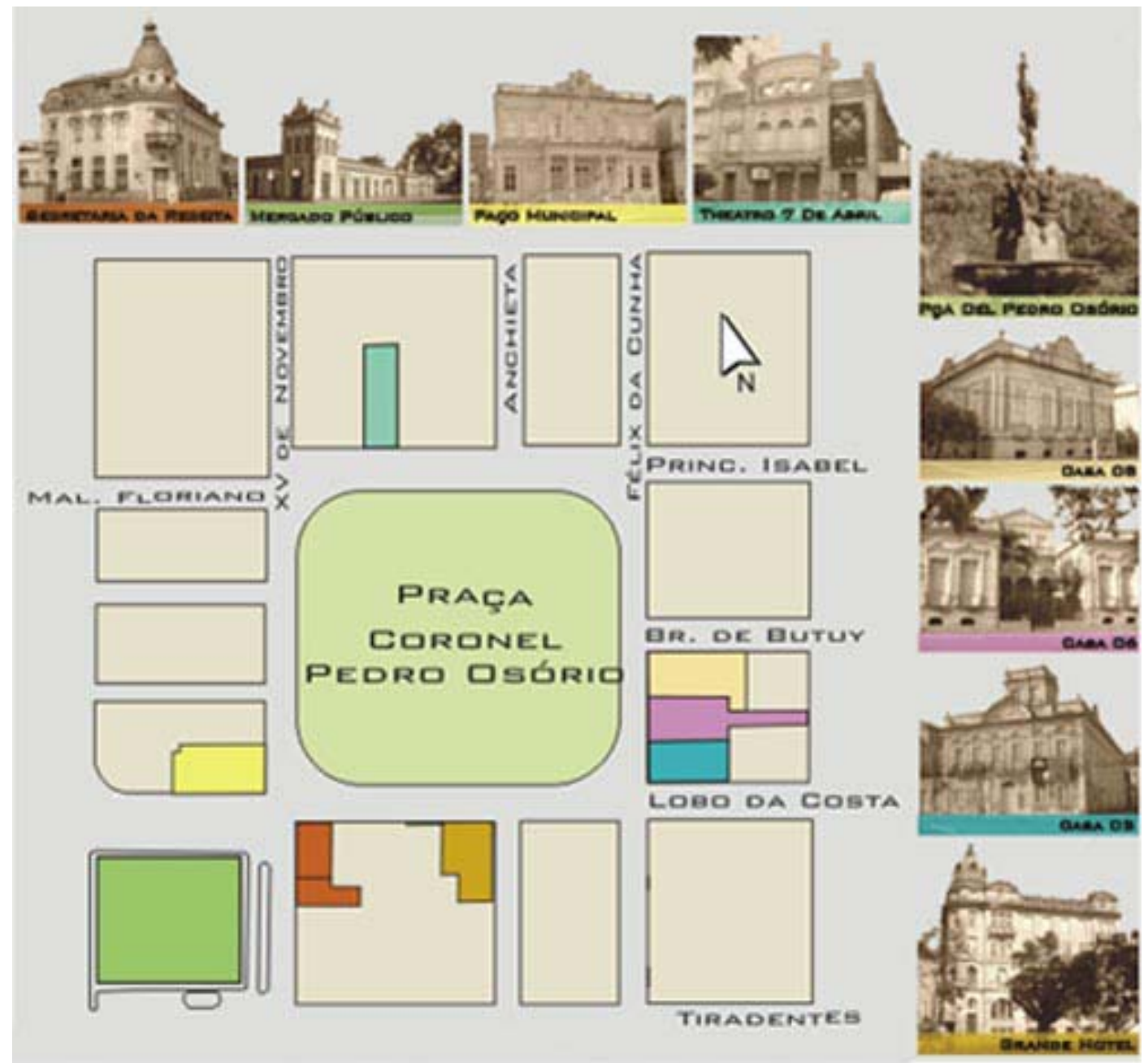

FIGURA 9 - Mapa da área de projeto do Programa Monumenta, com a localização dos bens culturais tombados em nivel federal - teatro sete de abril, casarões no 02, 06 e 08, estadual - casa da banha e municipal - grande hotel, prefeitura municipal e mercado público, bem como o prédio da Secretaria de Receita, bem inventariado pelo patrimônio cultural do município. Fonte: Acervo MONUMENTA. 


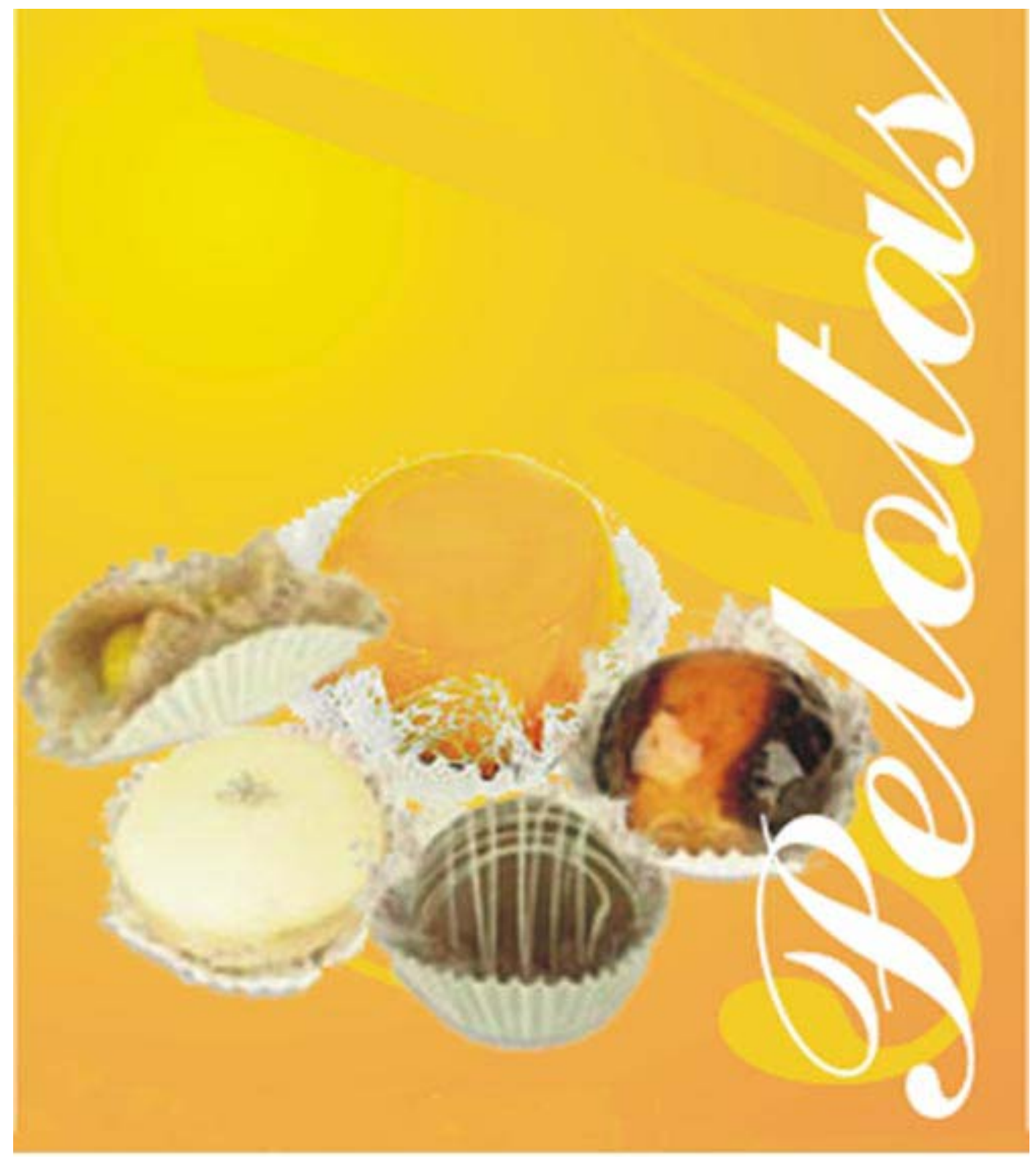

FIGURA 10 - Doces Tradicionais de Pelotas, referência cultural do município em processo de Inventário de Bens imateriais, através do projeto aprovado via Programa Monumenta. Fonte: Acervo SECULT.

\section{Notas}

(1) Mário Osório de Magalhães, historiador, professor da Universidade Federal de Pelotas, já realizou estudos importantes sobre a história de Pelotas como: Os passeios da cidade antiga: guia histórico das ruas de Pelotas e Pelotas: século XIX; Ester Judite Bendjouya Gutierrez, arquiteta e urbanista, Doutora em História pela PUC-RS e Especialista em Gestão do Patrimônio Cultural Integrado ao Planejamento pela UFPE-PE, autora de obras como Negros, Charqueadas e Olarias - um estudo sobre o espaço pelotense e Barro e Sangue, mão-de obra, arquitetura e urbanismo em Pelotas (1777-1888).

(2) Carne bovina, salgada e seca ao sol em mantas, produzida em estâncias conhecidas por "Charqueadas". 
(3) Protegido e reconhecido como Patrimônio Cultural do Estado do Rio Grande do Sul através da Lei $11895 / 2003$.

\section{Referências Bibliográficas}

GUTIERREZ, Éster Bendjouya. B. Barro e Sangue: mão-de-obra, arquitetura e urbanismo em Pelotas. (17771888). Pelotas: UFPEL, 2004. 549p.

LEMOS, Carlos. Alvenaria Burguesa. São Paulo: Estúdio Nobel, 1989. 206p.

MAGALHÃES, Mário Osório de. Pelotas: Século XIX. Pelotas: Livraria Mundial, 1994. 109p.

Os passeios da cidade antiga: guia histórico das ruas de Pelotas. Pelotas: Armazém Literário, 1994. $119 p$.

MEIRA, Ana Lúcia Goelzer. O passado no futuro da cidade: Políticas Públicas e Participação Popular na Preservação do Patrimônio Cultural de Porto Alegre. Porto Alegre: UFRGS, 2004. 207p.

MOURA, Rosa Rolim de. Modernidade Pelotense, A cidade e a Arquitetura Possível: 1940-1960. 1998. $185 f$. Dissertação (Especialização em História do Brasil) - Instituto de Filosofia e Ciências Humanas, Universidade Católica do Rio Grande do Sul, Porto Alegre, 1998.

PELOTAS. Lei Municipal no 4568, de 07 de julho de 2000. Estabelece áreas da cidade como zonas de preservação do Patrimônio Cultural de Pelotas - ZPPCs - lista seus bens e dá outras providências.

PELOTAS. Lei Municipal nº 5146, de 25 de julho de 2005. Reduz alíquotas do IPTU e dá outras providências.

PELOTAS. Lei Municipal nำ 2565, de 01 de setembro de 1980. Institui o II Plano Diretor de Pelotas.

PELOTAS. Lei Municipal no 2708, de 10 de maio de 1982. Dispõe sob a proteção do Patrimônio Histórico e Cultural do município de Pelotas e dá outras providências.

PELOTAS. Lei Municipal nำ3128, de 23 de julho de 1988. Altera a Lei municipal 2708/82.

ROIG, Carmem Vera. Futuro sem Pretérito?: As demolições do patrimônio edificado de Pelotas.1997. 67f. Monografia (Especialização em Patrimônio Cultural: Conservação de Artefatos) - Instituto de Letras e Artes, Universidade Federal de Pelotas, Pelotas, 1997.

*Arquiteta e Urbanista. Especialista em Patrimônio Cultural pela UFPEL (fase de conclusão). Funcionária da Prefeitura Municipal de Pelotas - Secretaria Municipal de Cultura - Diretoria da Memória e Patrimônio Cultural. 
**Arquiteta e Urbanista. Especialista em Restauração pela UFPEL (fase de conclusão). Funcionária da Prefeitura Municipal de Pelotas - Secretaria Municipal de Cultura - Diretoria da Memória e Patrimônio Cultural. 